\title{
Kerentanan DAS Cikeas ditinjau dari perspektif sosial ekonomi dan kelembagaan
}

\section{The vulnerability of the Cikeas watershed from a socio-economic and institutional perspective}

\author{
K. Prasetyo ${ }^{1 *}$, H. Effendi ${ }^{1,2}$, G. Prayoga ${ }^{1}$, A. R. Azhar ${ }^{1}$, T. Permadi ${ }^{1}$, D. Pratiwi ${ }^{3}$ \\ 1Pusat Penelitian Lingkungan Hidup, IPB University, Bogor, Indonesia \\ 2Departemen Manajemen Sumberdaya Perairan, Fakultas Perikanan dan Ilmu Kelautan, IPB University, \\ Bogor, Indonesia \\ 3Direktorat Jenderal Pengendalian Pencemaran dan Kerusakan Lingkungan, Kementerian Lingkungan \\ Hidup dan Kehutanan, Jakarta, Indonesia
}

\begin{abstract}
Abstrak.
Penelitian bertujuan menentukan tingkat kerentanan DAS Cikeas dilihat dari aspek sosial ekonomi dan kelembagaan. Metode pengumpulan data primer menganut purposive sampling dan snowball sampling. Data sekunder didapat dari Dinas Lingkungan Hidup (DLH), Balai Besar Wilayah Sungai (BBWS) Ciliwung Cisadane dan Badan Pusat Statistik (BPS). Analisis data menggunakan analisis deskriptif kuantitatif berdasarkan formulasi Sistem Karakterisasi Tingkat DAS (Tipologi DAS). Tingkat kerentanan DAS Cikeas ditinjau dari aspek sosial (kepadatan penduduk dan nilai tradisional) terkategori sangat tinggi (sangat rentan). Perilaku konservasi termasuk tidak rentan dan agak rentan. Pada aspek ekonomi, mayoritas kecamatan di wilayah DAS Cikeas tergolong agak rentan. Sektor ekonomi dominan berupa jasa. Ditinjau dari aspek kelembagaan, tergolong tidak rentan dan agak rentan karena kelembagaan formal dan informal ada yang telah berperan aktif dalam aktivitas konservasi DAS Cikeas. Permasalahan DAS berkaitan dengan kepedulian masyarakat terhadap pengelolaan lingkungan. Dengan demikian, keterlibatan masyarakat dan stakeholder terkait lainnya dalam perencanaan, perumusan, pelaksanaan kebijakan DAS sangat diperlukan untuk mencapai pengelolaan DAS berkelanjutan.
\end{abstract}

Kata kunci: DAS Cikeas, kerentanan, sosial ekonomi, kelembagaan

\begin{abstract}
.
The research aimed to determine the vulnerability level of the Cikeas watershed in terms of socio-economic and institutional aspects. The primary data collection method used purposive and snowball sampling. Secondary data were obtained from the Environmental Agency (DLH), Ciliwung Cisadane River Basin Center (BBWS) and Central Statistics Agency (BPS). Data analysis used quantitative descriptive analysis based on the formulation of watershed level characterization system. The vulnerability level of the Cikeas watershed in social aspects (population density and traditional values) was very high (very vulnerable). Conservation behaviour was classified as not vulnerable and somewhat vulnerable. On the economic aspect, most subdistricts in the Cikeas watershed were classified as somewhat vulnerable. The dominant economic sector was in the form of services. In terms of the institutional aspect, it was classified as not vulnerable and somewhat vulnerable because there were formal and informal institutions that have played an active role in the Cikeas watershed conservation activities. Watershed problems were related to the community's concern for environmental management. Thus, the involvement of the community and other relevant stakeholders in the planning, formulation, implementation of watershed policies was indispensable to achieve sustainable watershed management.
\end{abstract}

Keywords: Cikeas watershed, vulnerability, socio economic, institutional

\section{PENDAHULUAN}

Ekosistem perairan mengalir (lotik) yang mencirikan sungai berperan penting dalam menunjang langsung dan tak langsung kehidupan manusia. Aktivitas di sekitar perairan berpotensi mempengaruhi dan mengalterasi kondisi lingkungan perairan. Selanjutnya dapat menimbulkan akibat tak baik terhadap biota yang hidup di perairan dan bagi masyarakat sebagai pemanfaat

\footnotetext{
* Korespondensi Penulis

Email : kunandarp@gmail.com
} 
sumber daya perairan. Perubahan lahan riparian di daerah aliran sungai (DAS) bagian hulu menjadi salah satu pemicu utama berkurangnya kapabilitas tanah dalam menahan masuknya unsur hara secara berlebihan ke badan air. Beralihnya peruntukan lahan menjadi pertanian, perkebunan, permukiman, industri, pertambangan berpotensi mengakibatkan penurunan kualitas perairan (Tafangenyasha and Dzinomwa 2005; Suparjo 2009).

Sungai Cikeas adalah salah satu sungai di Kabupaten Bogor, Provinsi Jawa Barat, yang mengalir dari selatan ke utara dan kemudian bergabung dengan Sungai Cileungsi menjadi Sungai Bekasi (Kali Bekasi). Tata guna lahan dan aktivitas di bagian hulu Sungai Cikeas beragam. Aktivitas perumahan ditemukan pada beberapa segmen. Diperlukan pengelolaan yang baik agar tidak memunculkan pengaruh negatif terhadap kualitas perairan sungai. Penggunaan lahan berhubungan kuat dengan kegiatan manusia, berpotensi mengakibatkan gangguan terhadap keseimbangan ekosistem di DAS (Komaruddin 2008).

Kajian untuk meningkatkan kualitas air melalui restorasi daerah tangkapan air dan penguatan sosial pada DAS Cikeas perlu dilakukan. Sesuai dengan PerMenLH Nomor 1 Tahun 2010 tentang Tata Laksana Pengendalian Pencemaran, pemerintah memiliki kewenangan melaksanakan inventarisasi dan identifikasi sumber pencemar dan kerusakan lingkungan. Berdasarkan hal tersebut, identifikasi dan inventarisasi sumber pencemar dan kerusakan lingkungan perlu dilaksanakan untuk mengetahui faktor yang menyebabkan penurunan kualitas air. Selanjutnya, dapat disusun rekomendasi upaya pengendalian pencemaran air dan konservasi sumber daya air. Tujuan penelitian adalah mengidentifikasi tingkat kerentanan sosial, ekonomi dan kelembagaan masyarakat yang selanjutnya dapat digunakan dalam pertimbangan perencanaan pengelolaan DAS Cikeas. Hasil studi ini berupa pemetaan kondisi sosial mencakup pemetaan tiga aspek tingkat kerentanan.

\section{METODOLOGI}

\subsection{Lokasi kajian dan waktu penelitian}

Penelitian dilaksanakan di wilayah DAS Kali Cikeas pada November 2019. DAS Kali Cikeas mengalir di wilayah Kabupaten Bogor, Kota Depok dan Kota Bekasi yang meliputi Kecamatan Babakan Madang, Kecamatan Sukaraja, Kecamatan Citeureup, Kecamatan Cibinong, Kecamatan Gunung Putri, Kecamatan Tapos, Kecamatan Jatisampurna dan Kecamatan Jatiasih.

\subsection{Prosedur analisis data}

Observasi lapang dan wawancara mendalam (in depth interview) terhadap aparat desa, tokoh masyarakat dan kelompok masyarakat yang berperan aktif pada upaya konservasi DAS dilakukan untuk memperoleh data primer. Data 
sekunder didapatkan dari Dinas Lingkungan Hidup (DLH), Balai Besar Wilayah Sungai (BBWS) Ciliwung Cisadane dan Badan Pusat Statistik (BPS). Metode pengambilan sampel menggunakan dua metode. Metode yang pertama yaitu purposive sampling, merupakan cara pengambilan sampel yang mempertimbangkan hal tertentu, dimaksudkan agar data bisa lebih representatif. Purposive dilakukan terhadap para narasumber kunci yang mengetahui dan memiliki pengetahuan tentang obyek penelitian, seperti pejabat pemerintah daerah, tokoh masyarakat, tokoh agama, dsb. Metode kedua menggunakan snowball sampling, adalah cara penentuan sampel yang semula berjumlah sedikit, lalu responden ini diminta memilih koleganya untuk dijadikan responden juga (Sugiyono 2016).

Identifikasi terhadap tiga tingkat kerentanan yaitu kerentanan sosial, ekonomi dan kelembagaan mengacu pada metode yang diformulasi oleh Paimin et al. (2012). Karakteristik DAS Kali Cikeas ditinjau dari: 1) aspek sosial berupa tekanan penduduk, budaya dan nilai tradisional; 2) aspek ekonomi yang berhubungan dengan ketergantungan terhadap lahan ditinjau dari sektor ekonomi dominan, selanjutnya dikomparasikan dengan tingkat kepadatan penduduk; 3) aspek kelembagaan yang berkaitan dengan keberdayaan lembaga formal dan informal dalam upaya konservasi. Penentuan kriteria sosial dan kelembagaan dilaksanakan dengan mengacu pada Tabel 1, sedangkan kriteria ekonomi mengacu kepada Tabel 2. Semua hasil pengukuran parameter sosial, ekonomi dan kelembagaan diklasifikasikan tingkat kerentanannya menurut Tabel 3 (Paimin et al. 2012).

Tabel 1. Kriteria dan parameter kerentanan sosial dan kelembagaan.

\begin{tabular}{|c|c|c|c|}
\hline Kriteria & Parameter & Besaran & Skor \\
\hline \multirow{13}{*}{ Sosial } & \multirow{3}{*}{ Kepadatan penduduk } & $<250$ jiwa $/ \mathrm{km}^{2}$ & 1 \\
\hline & & $250-400$ jiwa $/ \mathrm{km}^{2}$ & 3 \\
\hline & & $>400$ jiwa $/ \mathrm{km}^{2}$ & 5 \\
\hline & \multirow{3}{*}{$\begin{array}{l}\text { Budaya: Perilaku } \\
\text { konservasi }\end{array}$} & $\begin{array}{l}\text { Konservasi telah melembaga di } \\
\text { masyarakat (paham manfaat, paham } \\
\text { teknik dan pelaksanaannya) }\end{array}$ & 1 \\
\hline & & $\begin{array}{l}\text { Masyarakat tahu, namun tidak } \\
\text { melaksanakan }\end{array}$ & 3 \\
\hline & & Tidak tahu dan tidak melaksanakan & 5 \\
\hline & \multirow{5}{*}{ Budaya: Hukum adat } & Adat istiadat, pelanggar dikucilkan & 1 \\
\hline & & Kebiasaan, pelanggar didenda secara adat & 2 \\
\hline & & $\begin{array}{l}\text { Tata kelakuan, pelanggar ditegur ketua } \\
\text { adat/orang lain }\end{array}$ & 3 \\
\hline & & Cara, pelanggar dicemooh & 4 \\
\hline & & Tidak ada hukuman & 5 \\
\hline & \multirow{2}{*}{ Nilai tradisional } & Ada & 1 \\
\hline & & Tidak ada & 5 \\
\hline
\end{tabular}




\begin{tabular}{lllc}
\hline Kriteria & Parameter & Besaran & Skor \\
\hline \multirow{4}{*}{ Kelembagaan } & Keberdayaan & Ada dan berperan & 1 \\
& kelembagaan informal & Ada, namun tidak berperan & 3 \\
& konservasi & Tidak berperan & 5 \\
\cline { 2 - 4 } & Keberdayaan & Sangat berperan & 1 \\
& kelembagaan formal & Cukup berperan & 3 \\
& konservasi & Tidak berperan & 5 \\
\hline
\end{tabular}

Tabel 2. Kriteria dan parameter kerentanan ekonomi.

\begin{tabular}{lccc}
\hline \multirow{2}{*}{ Kepadatan penduduk (orang $/ \mathrm{km}^{2}$ ) } & \multicolumn{3}{c}{ Struktur ekonomi } \\
\cline { 2 - 4 } & Pertanian & Industri & Jasa \\
\hline Jarang $(<250)$ & 3 & 2 & 1 \\
Sedang $(250-400)$ & 4 & 3 & 2 \\
Padat $(>400)$ & 5 & 4 & 3 \\
\hline
\end{tabular}

Tabel 3. Klasifikasi tingkat kerentanan sosial, ekonomi dan kelembagaan.

\begin{tabular}{ccc}
\hline Kategori & Nilai & Tingkat kerentanan/degradasi \\
\hline Sangat tinggi & $>4,3$ & Sangat rentan/Sangat terdegradasi \\
Tinggi & $3,5-4,3$ & Rentan/Terdegradasi \\
Sedang & $2,6-3,4$ & Agak rentan \\
Rendah & $1,7-2,5$ & Sedikit rentan/Agak terdegradasi \\
Sangat rendah & $<1,7$ & Tidak rentan/Tidak terdegradasi \\
\hline
\end{tabular}

\section{HASIL DAN PEMBAHASAN}

\subsection{Sosial}

\subsubsection{Indikator pertumbuhan dan kepadatan penduduk}

Berdasarkan Tabel 4, diketahui jumlah penduduk delapan kecamatan yang masuk pada DAS Cikeas sebanyak 2,04 juta jiwa (1,03 juta laki-laki dan 1,01 juta perempuan). Jumlah penduduk terbanyak dan yang memiliki laju pertumbuhan penduduk per tahun tertinggi terdapat di Kecamatan Gunung Putri, sedangkan yang terendah di Kecamatan Sukaraja. Rata-rata jumlah penduduk di DAS Cikeas sebesar 251.092 jiwa dengan kepadatan penduduk ratarata 5.581 jiwa $/ \mathrm{km}^{2}$ (Tabel 5). Merujuk pada Paimin et al. (2012), nilai kepadatan penduduk di DAS Cikeas termasuk kategori sangat tinggi ( $>400$ jiwa $/ \mathrm{km}^{2}$ ). Kecamatan dengan tingkat kepadatan penduduk tertinggi adalah Kecamatan Cibinong sebesar 10.327 jiwa $/ \mathrm{km}^{2}$ dan kepadatan penduduk terendah ada di Kecamatan Babakan Madang sebesar $1.657 \mathrm{jiwa} / \mathrm{km}^{2}$. Cepatnya pertumbuhan penduduk memerlukan daerah baru untuk pemenuhan kebutuhan primer. Selanjutnya, menyebabkan penggunaan lahan yang tidak cocok dengan potensi dan melampaui daya dukung (Symeonakis et al. 2007). Lebih lanjut menurut Ekawaty et al. (2018), inti permasalahan yang muncul di kawasan DAS adalah pertumbuhan penduduk, sebab peningkatan jumlah penduduk akan juga meningkatkan kebutuhan hidup. 
Tabel 4. Jumlah penduduk berdasarkan jenis kelamin dan pertumbuhan penduduk pada masing-masing kecamatan di DAS Cikeas tahun 2018.

\begin{tabular}{lrrrr}
\hline \multirow{2}{*}{ Kecamatan } & \multicolumn{3}{c}{ Jenis Kelamin } & \multirow{2}{*}{ Pertumbuhan penduduk (\%) } \\
\cline { 2 - 4 } & Laki-laki & Perempuan & Jumlah & \\
\hline Babakan Madang & 65.576 & 61.959 & 127.535 & 2,26 \\
Sukaraja & 30.065 & 27.816 & 57.881 & 0,10 \\
Citeureup & 120.013 & 115.503 & 235.516 & 1,74 \\
Cibinong & 223.770 & 217.627 & 441.397 & 3,37 \\
Gunung Putri & 235.316 & 241.096 & 476.412 & 5,01 \\
Tapos & 145.498 & 144.311 & 289.809 & 3,46 \\
Jatisampurna & 76.442 & 78.074 & 154.516 & 4,46 \\
Jatiasih & 130.256 & 128.195 & 258.451 & 2,85 \\
\hline \multicolumn{1}{c}{ Jumlah } & 1.026 .936 & 1.014 .581 & 2.041 .517 & - \\
\hline Sumber: BPS Kabupaten Bogor (2019), BPS Kota Bekasi (2019) dan BPS Kota Depok (2019) (diolah).
\end{tabular}

Tabel 5. Kepadatan penduduk menurut kecamatan di DAS Cikeas tahun 2018.

\begin{tabular}{lcccccc}
\hline Kecamatan & $\begin{array}{c}\text { Jumlah } \\
\text { penduduk } \\
\text { (jiwa) }\end{array}$ & $\begin{array}{c}\text { Luas } \\
\text { wilayah } \\
\left(\mathrm{km}^{2}\right)\end{array}$ & $\begin{array}{c}\text { Kepadatan } \\
\text { penduduk } \\
\text { (jiwa/km²) }\end{array}$ & Skor & Kategori & $\begin{array}{c}\text { Tingkat } \\
\text { kerentanan }\end{array}$ \\
\hline Babakan Madang & 126.777 & 76,53 & 1.657 & 5 & Sangat tinggi & Sangat rentan \\
Sukaraja & 182.123 & 42,10 & 4.326 & 5 & Sangat tinggi & Sangat rentan \\
Citeureup & 235.822 & 67,10 & 3.514 & 5 & Sangat tinggi & Sangat rentan \\
Cibinong & 447.052 & 43,29 & 10.327 & 5 & Sangat tinggi & Sangat rentan \\
Gunung Putri & 475.498 & 56,00 & 8.491 & 5 & Sangat tinggi & Sangat rentan \\
Tapos & 240.147 & 33,26 & 8.713 & 5 & Sangat tinggi & Sangat rentan \\
Jatisampurna & 154.516 & 19,54 & 7.907 & 5 & Sangat tinggi & Sangat rentan \\
Jatiasih & 258.451 & 24,27 & 8.458 & 5 & Sangat tinggi & Sangat rentan \\
\hline \multicolumn{1}{c}{ Rata-rata } & 251.092 & 44,99 & 5.581 & 5 & Sangat tinggi & Sangat rentan \\
\hline
\end{tabular}

Sumber: BPS Kabupaten Bogor (2019), BPS Kota Bekasi (2019) dan BPS Kota Depok (2019) (diolah).

Secara spasial tingkat kerentanan DAS Cikeas berdasarkan indikator kepadatan penduduk disajikan pada Gambar 1. Semua kecamatan yang termasuk dalam DAS Cikeas tergolong sangat rentan. Hal ini terjadi akibat kepadatan penduduk yang tergolong sangat tinggi. Kepadatan penduduk yang sangat tinggi ini diakibatkan beberapa wilayah di DAS Cikeas merupakan kawasan industri. Tingginya kepadatan penduduk tersebut mengakibatkan peningkatan beban polutan, kualitas air memburuk dan ekosistem terdegradasi. Dengan demikian, kepadatan penduduk yang tinggi akan diiringi dengan aktivitas antropogenik yang berpengaruh nyata terhadap keseimbangan lingkungan dan penurunan kualitas lingkungan seperti terjadinya erosi, kurangnya daerah resapan air, banjir, pendangkalan sungai, dan penurunan kualitas air (Prasetyo et al. 2020). Tekanan penduduk yang tinggi mengakibatkan tekanan pada lahan, melalui penggunaan yang berlebihan, sehingga akan menyebabkan terjadinya degradasi pada lahan dan melampaui kemampuan dan daya dukung alaminya (Goldshleger et al. 2010). 


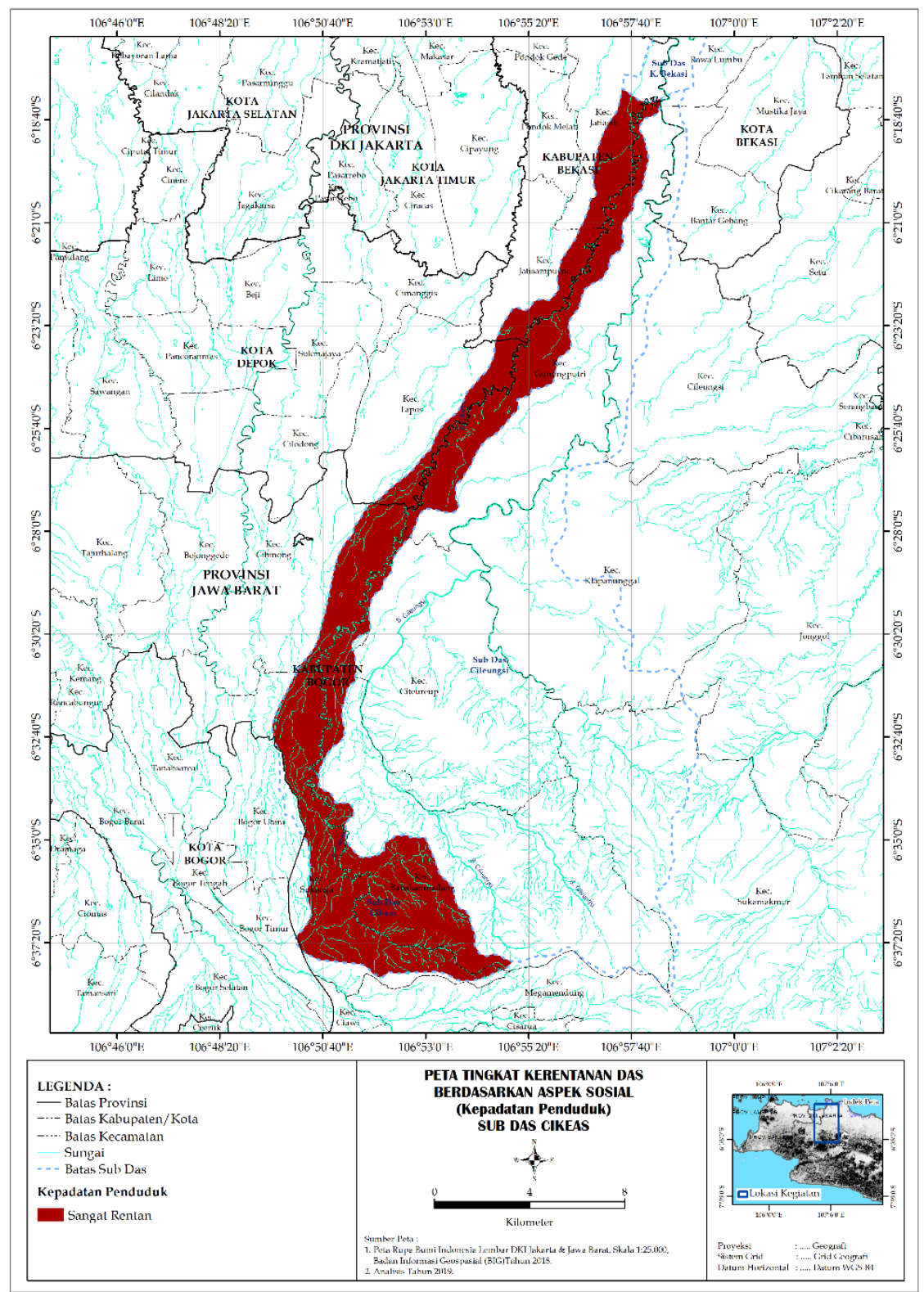

Gambar 1. Tingkat kerentanan DAS Cikeas berdasarkan indikator kepadatan penduduk.

\subsubsection{Indikator budaya}

Parameter budaya terdiri perilaku konservasi dan hukum adat. Perilaku konservasi menggambarkan pengetahuan masyarakat dan pelembagaan konservasi di dalam masyarakat. Bentuk konservasi sungai yang dikaji pada penelitian ini meliputi pola membuang sampah rumah tangga dalam kaitannya untuk menjaga kualitas air Sungai Cikeas. 
Berdasarkan Tabel 6, diketahui bahwa hanya ada dua dari lima desa/kelurahan yang telah melakukan konservasi tanah dan air yaitu Desa Bojong Kulur dan Kelurahan Tapos. Perilaku konservasi yang telah melembaga tersebut dapat mengurangi kerusakan Sungai Cikeas, sehingga kedua desa tergolong tidak rentan. Hasil wawancara dengan perangkat desa dan tokoh masyarakat, serta pengamatan lapangan menunjukkan mayoritas masyarakat di lokasi studi sudah mengetahui dampak negatif dan positif dari perilaku konservasi berupa pola pembuangan sampah. Masyarakat mengetahui bahwa membuang sampah ke Sungai Cikeas akan menyebabkan pencemaran air sungai. Namun demikian, sejumlah masyarakat masih membuang sampah ke sungai atau bantaran sungai. Hal ini karena minimnya sarana dan prasarana pengelolaan sampah seperti tempat pembuangan sementara, tidak adanya petugas kebersihan dan biaya kebersihan yang mahal. Desa Bojong Kulur yang merupakan area perumahan telah melakukan pengelolaan sampah dengan baik.

Tabel 6. Perilaku konservasi masyarakat di DAS Cikeas.

\begin{tabular}{|c|c|c|c|c|}
\hline $\begin{array}{l}\text { Desa/ } \\
\text { Kelurahan }\end{array}$ & Perilaku konservasi & Skor & Kategori & $\begin{array}{c}\text { Tingkat } \\
\text { kerentanan }\end{array}$ \\
\hline Bojong Kulur & $\begin{array}{l}\text { Masyarakat tahu manfaat dan teknik } \\
\text { konservasi tetapi tidak melakukan }\end{array}$ & 1 & Sangat rendah & Tidak rentan \\
\hline Cikeas & $\begin{array}{l}\text { Masyarakat tahu manfaat dan teknik } \\
\text { konservasi tetapi tidak melakukan }\end{array}$ & 3 & Sedang & Agak Rentan \\
\hline Nagrak & $\begin{array}{l}\text { Masyarakat tahu manfaat dan teknik } \\
\text { konservasi tetapi tidak melakukan }\end{array}$ & 3 & Sedang & Agak Rentan \\
\hline Karanggan & $\begin{array}{l}\text { Masyarakat tahu manfaat dan teknik } \\
\text { konservasi tetapi tidak melakukan }\end{array}$ & 3 & Sedang & Agak Rentan \\
\hline Tapos & $\begin{array}{l}\text { Masyarakat tahu manfaat dan teknik } \\
\text { konservasi tetapi tidak melakukan }\end{array}$ & 1 & Sangat rendah & Tidak rentan \\
\hline
\end{tabular}

Secara spasial, terdapat dua desa yang termasuk tidak rentan (warna hijau) dan tiga desa termasuk agak rentan (warna oranye) (Gambar 2). Seluruh desa di lokasi studi telah memiliki pengetahuan tentang manfaat konservasi DAS dan peran penting tindakan konservasi bagi kelestarian DAS. Hal ini menunjukkan telah adanya kesadaran masyarakat yang menimbulkan rasa ikut memiliki atas sungai yang sifatnya open acces dan common property. Hal ini tergolong pada tingkat kerentanan/degradasi sungai yang tidak rentan, karena sudah muncul kesadaran yang kemudian diaktualisasikan dalam aksi nyata konservasi DAS. Menurut Susilowati et al. (2012) dan Du et al. (2018), kesadaran masyarakat akan pentingnya memelihara kelestarian lingkungan merupakan kunci utama keberhasilan dalam menjaga kelestarian lingkungan seperti DAS, karena akan menimbulkan rasa tanggung jawab terhadap lingkungan yang memunculkan tindakan konservasi untuk menjaga keberlanjutan lingkungan. Oleh karena itu masyarakat perlu diberdayakan dalam pengelolaan lingkungan. 


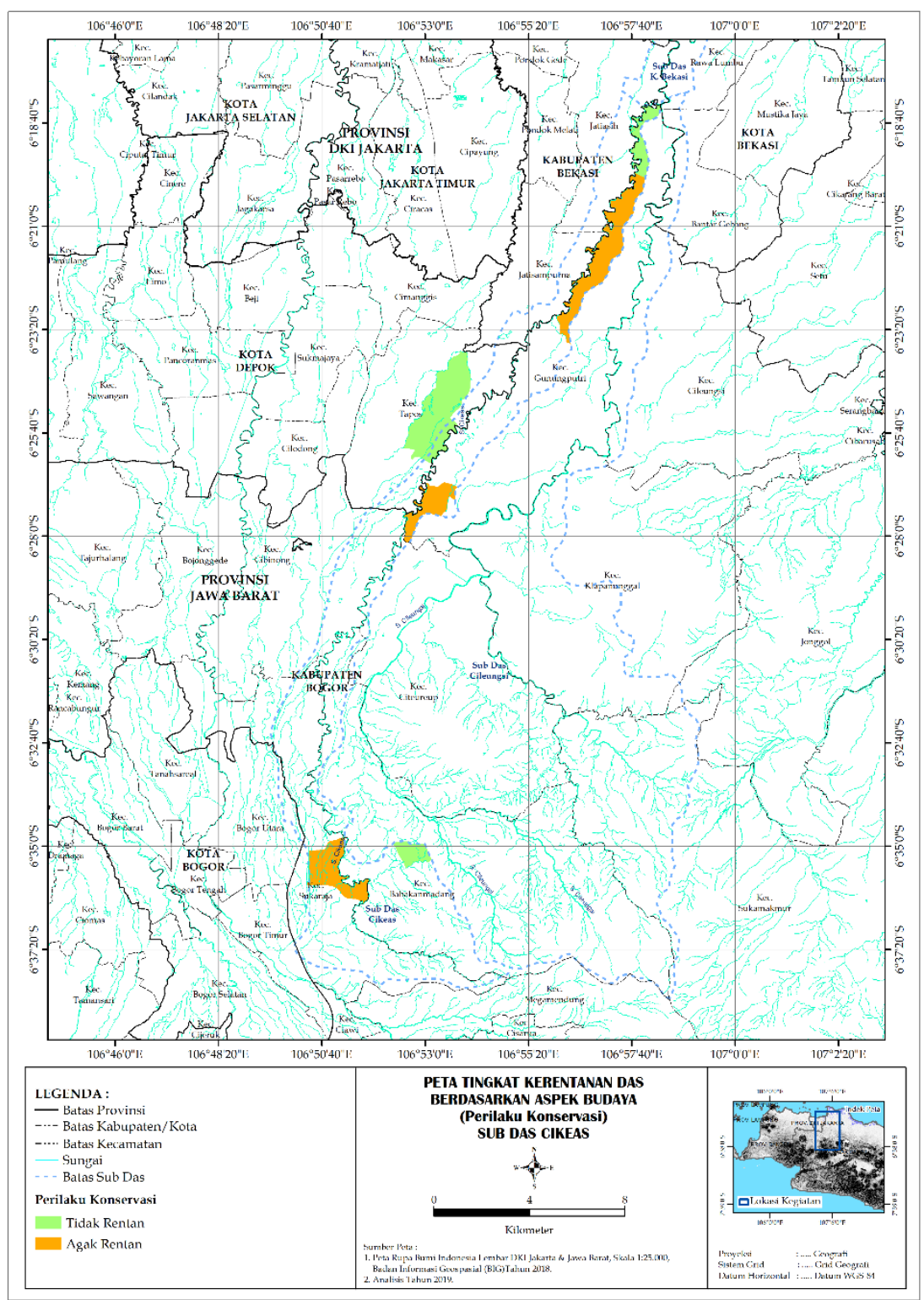

Gambar 2. Tingkat kerentanan DAS Cikeas berdasarkan indikator perilaku konservasi.

\subsubsection{Indikator nilai tradisional}

Data nilai tradisional di DAS Cikeas merupakan hasil wawancara dengan perangkat desa dan tokoh masyarakat. Berdasarkan hasil wawancara, tidak ditemukan nilai tradisional yang diajarkan atau dilestarikan oleh masyarakat setempat. Berdasarkan sidik cepat degradasi DAS (Paimin et al. 2012), diperoleh skor sebesar 5 pada seluruh lokasi pengamatan yang berarti memiliki tingkat kerentanan yang sangat rentan (Tabel 7). Hal ini menandakan bahwa sudah 
tidak ada nilai-nilai tradisional yang secara turun-temurun diajarkan, dilaksanakan dan dilestarikan. Dampak dari hal tersebut adalah dapat menimbulkan tindakan masyarakat yang dapat menurunkan/merusak kualitas DAS seperti perilaku membuang sampah ke sungai, menambang pasir di sungai tanpa memperhatikan aspek lingkungan, dsb. Hal ini akibat tidak adanya pengatur perilaku masyarakat untuk menjaga dan melestarikan sungai, sehingga masyarakat tidak merasa bersalah secara moral jika melakukan tindakan yang dapat merusak sungai.

Tabel 7. Nilai tradisional di DAS Cikeas.

\begin{tabular}{lcccc}
\hline Desa/Kelurahan & $\begin{array}{c}\text { Nilai } \\
\text { tradisional }\end{array}$ & Skor & Kategori & Tingkat kerentanan \\
\hline Bojong Kulur & Tidak ada & 5 & Sangat tinggi & Sangat rentan/Sangat terdegradasi \\
Cikeas & Tidak ada & 5 & Sangat tinggi & Sangat rentan/Sangat terdegradasi \\
Nagrak & Tidak ada & 5 & Sangat tinggi & Sangat rentan/Sangat terdegradasi \\
Karanggan & Tidak ada & 5 & Sangat tinggi & Sangat rentan/Sangat terdegradasi \\
Tapos & Tidak ada & 5 & Sangat tinggi & Sangat rentan/Sangat terdegradasi \\
\hline
\end{tabular}

Secara spasial, tingkat kerentanan DAS Cikeas berdasarkan indikator nilai tradisional disajikan pada Gambar 3. Seluruh desa di lokasi studi termasuk dalam tingkat sangat rentan/sangat terdegradasi. Hal ini karena sudah tidak adanya nilai tradisional atau kearifan lokal (local wisdom) dalam kehidupan sehari-hari yang diperoleh dari ajaran langsung orang tua kepada anak/cucu. Keberadaan nilai tradisional ini sangat menguntungkan, karena sangat membantu dalam mencegah terjadinya kerusakan lingkungan baik secara langsung maupun tidak. Terjadinya degradasi nilai tradisional tidak terlepas dari perubahan norma sosial menjadi norma yang lebih modern yang lebih berorientasi pada kesejahteraan ekonomi (hedonisme). Kearifan lokal merupakan modal sosial pada perspektif pembangunan berkelanjutan berwawasan lingkungan. Pelestarian nilai-nilai kearifan lokal menjadi salah satu strategi perlindungan dan pengelolaan lingkungan hidup. Oleh karenanya, penting untuk dikaji dan diposisikan strategis menuju pengelolaan sumber daya alam dan lingkungan yang lebih baik (Siswadi et al. 2011).

\subsection{Ekonomi}

Berdasarkan data BPS Kabupaten Bogor (2019), BPS Kota Bekasi (2019) dan BPS Kota Depok (2019), struktur ekonomi dominan di masing-masing kecamatan pada DAS Cikeas adalah sektor ekonomi sekunder (industri) dan tersier (jasa). Kecamatan dengan perekonomian dominan industri yaitu Kecamatan Citeureup dan Gunung Putri, sedangkan sebanyak enam kecamatan lainnya memiliki struktur ekonomi dominan dari sektor jasa meliputi restoran/ rumah makan, hotel, perumahan, dan jasa kemasyarakatan lainnya (Tabel 8). 


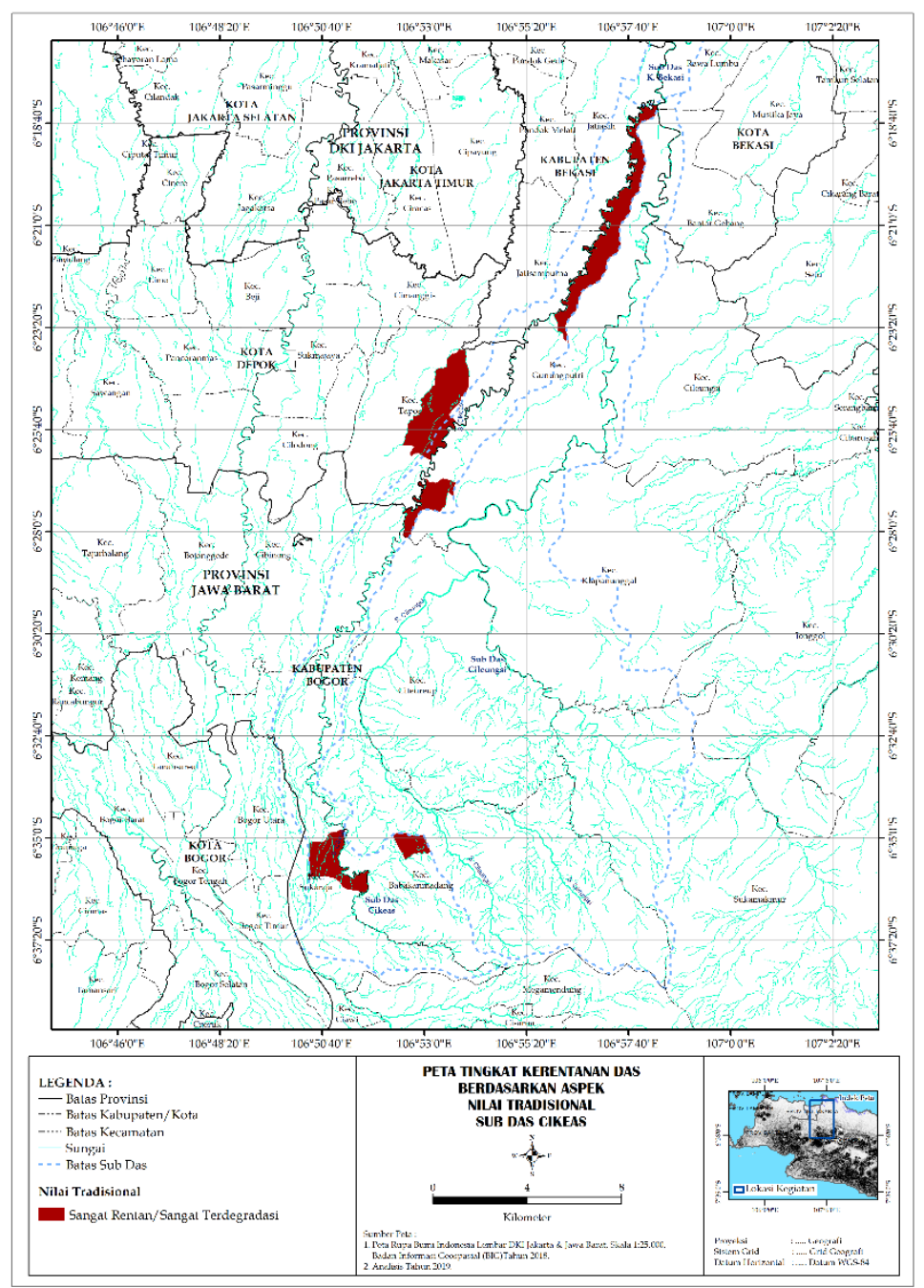

Gambar 3. Tingkat kerentanan DAS Cikeas berdasarkan indikator nilai tradisional.

Tabel 8. Kerentanan penduduk terhadap lahan di DAS Cikeas tahun 2018.

\begin{tabular}{|c|c|c|c|c|c|}
\hline Kecamatan & $\begin{array}{l}\text { Luas wilayah } \\
\qquad\left(\mathrm{km}^{2}\right)\end{array}$ & $\begin{array}{l}\text { Kepadatan } \\
\text { penduduk } \\
\left(\text { jiwa } / \mathrm{km}^{2} \text { ) }\right.\end{array}$ & $\begin{array}{l}\text { Struktur } \\
\text { ekonomi } \\
\text { dominan }\end{array}$ & Skor & $\begin{array}{l}\text { Tingkat } \\
\text { kerentanan }\end{array}$ \\
\hline Babakan Madang & 76,53 & 1.657 & Jasa & 3 & Agak rentan \\
\hline Sukaraja & 42,10 & 4.326 & Jasa & 3 & Agak rentan \\
\hline Citeureup & 67,10 & 3.514 & Industri & 4 & Rentan \\
\hline Cibinong & 43,29 & 10.327 & Jasa & 3 & Agak rentan \\
\hline Gunung Putri & 56,00 & 8.491 & Industri & 4 & Rentan \\
\hline Tapos & 32,33 & 7.428 & Jasa & 3 & Agak rentan \\
\hline Jatisampurna & 19,54 & 5.448 & Jasa & 3 & Agak rentan \\
\hline Jatiasih & 23,04 & 8.458 & Jasa & 3 & Agak rentan \\
\hline
\end{tabular}


Secara spasial, tingkat kerentanan DAS Cikeas berdasarkan indikator struktur ekonomi disajikan pada Gambar 4. Sebanyak enam dari delapan kecamatan di DAS Cikeas terkategori agak rentan, sedangkan dua kecamatan lainnya yaitu Citeureup dan Gunung Putri tergolong rentan, karena struktur ekonomi dominannya pada sektor industri. Keberadaan industri yang ada di wilayah DAS Cikeas berpotensi memberikan dampak pencemaran pada air sungai, karena pembuangan limbah secara langsung ke sungai. Dari sektor jasa, kerentanan DAS biasanya bersumber dari sampah domestik yang dihasilkan. Hal ini terkonfirmasi dengan kondisi DAS Cikeas yang masih alami, warna air bening kecokelatan dan bantaran sungai didominasi vegetasi.

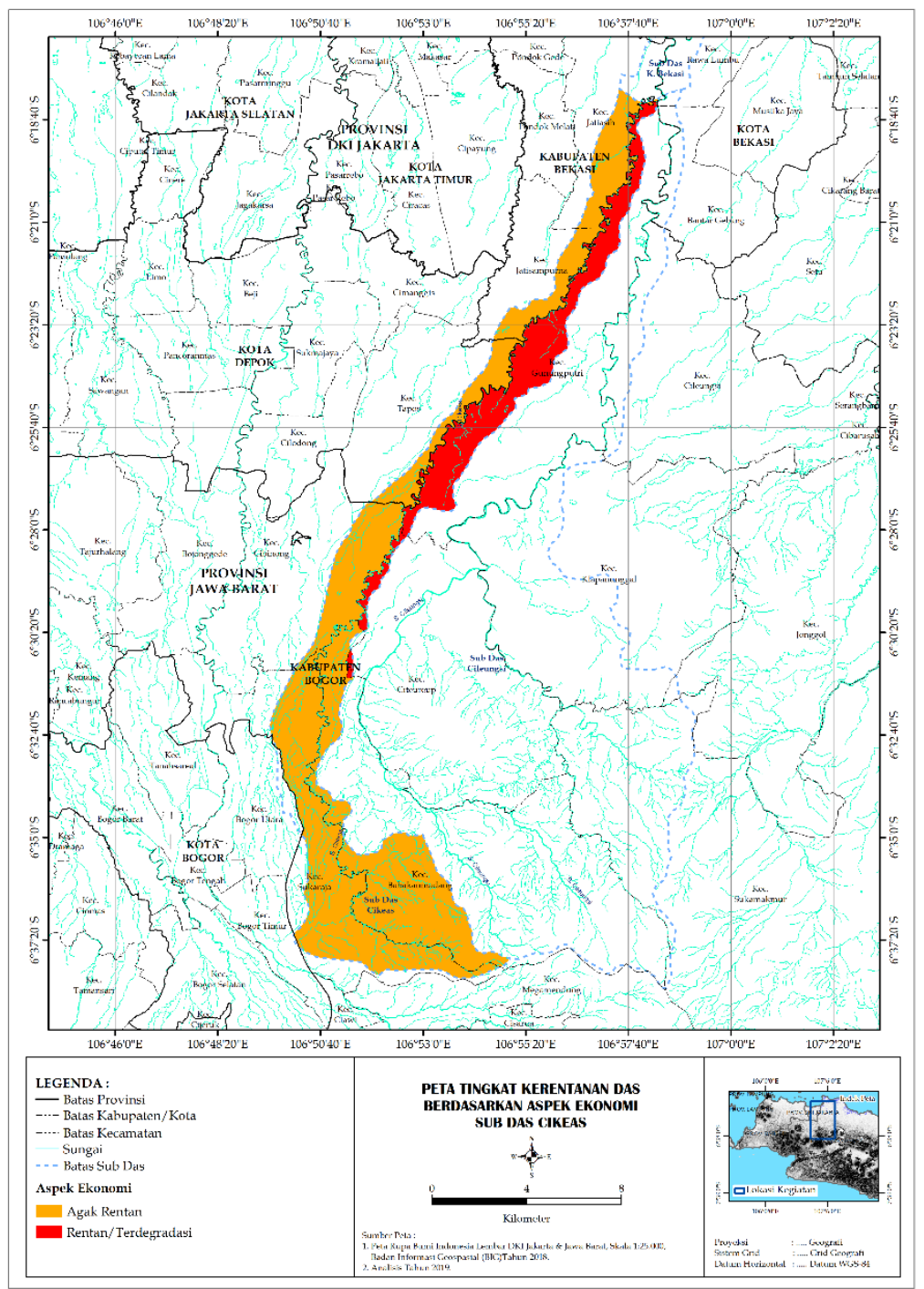

Gambar 4. Tingkat kerentanan DAS Cikeas berdasarkan indikator struktur ekonomi. 


\subsection{Kelembagaan}

Kelembagaan berkaitan dengan keberdayaan lembaga informal dan formal. Keberdayaan lembaga informal pada kegiatan konservasi berupa pengajian, kelompok arisan, perkumpulan masyarakat, dll. yang perannya perlu dipertimbangkan pada upaya konservasi. Keberdayaan lembaga formal pada aktivitas konservasi memperlihatkan peran lembaga formal dalam kegiatan konservasi. Kelembagaan formal mencakup: jenis lembaga (kelompok tani, LMDH, BPD, dll.), tujuan lembaga, struktur organisasi, fungsi lembaga (informasi, keterlibatan anggota dalam perencanaan, pelaksanaan dan evaluasi kegiatan, serta peran serta anggota dalam pertemuan rutin, kewajiban dalam lembaga, dan pencarian informasi), pembinaan dan pemeliharaan lembaga.

Tabel 9 menunjukkan keberdayaan kelembagaan informal pada kegiatan konservasi di DAS Cikeas. Hanya dua dari lima desa yang memiliki kelembagaan informal yang berperan aktif dalam konservasi dan pelestarian DAS yaitu Desa Bojong Kulur dan Desa Cikeas. Kelembagaan di Desa Bojong Kulur berupa komunitas pelestarian sungai yaitu Komunitas Peduli Sungai Cileungsi dan Cikeas (KP2C) yang aktif melakukan kegiatan konservasi dan pelestarian Sungai Cikeas dan Cileungsi. Salah satu kegiatan yang dilakukan adalah pembersihan sampah bambu yang menumpuk di Bendung Koja, bekerja sama dengan DLH Kabupaten Bogor dan Kota Bekasi, serta berbagai instansi lainnya. Oleh karena itu, kondisi DAS Cikeas pada Desa Bojong Kulur dan Cikeas termasuk kategori tidak rentan/tidak terdegradasi.

Tabel 9. Kriteria kelembagaan di DAS Cikeas.

\begin{tabular}{llccc}
\hline Desa/Kelurahan & $\begin{array}{l}\text { Keberdayaan } \\
\text { kelembagaan informal }\end{array}$ & Skor & Kategori & Tingkat kerentanan \\
\hline Bojong Kulur & $\begin{array}{l}\text { LSM berperan aktif } \\
\text { dalam konservasi }\end{array}$ & 1 & Sangat rendah & $\begin{array}{c}\text { Tidak rentan/ } \\
\text { Tidak terdegradasi } \\
\text { Tidak rentan/ }\end{array}$ \\
Cikeas & $\begin{array}{l}\text { Kelompok masyarakat } \\
\text { berperan aktif }\end{array}$ & 1 & Sangat rendah & $\begin{array}{c}\text { Tidak terdegradasi } \\
\text { Nagrak }\end{array}$ \\
Karanggan & Kurang berperan & 3 & Sedang & Agak Rentan \\
Tapos & Kurang berperan & 3 & Sedang & Agak Rentan \\
\hline
\end{tabular}

Secara spasial, diketahui bahwa dua dari lima desa di lokasi studi termasuk kategori tidak rentan/tidak terdegradasi, sedangkan tiga desa lainnya termasuk agak rentan (Gambar 5). Keberdayaan kelompok informal dalam melakukan kegiatan konservasi mengindikasikan masyarakat telah memiliki kesadaran kolektif mengenai peran penting dari air dan upaya pelestarian sumber dayanya bagi kehidupan. Dengan upaya-upaya konservasi yang dilakukan oleh kelembagaan informal tersebut, akan membuat DAS terhindar dari kerusakan/degradasi. Desa-desa yang kelembagaan informalnya masih belum 
berperan aktif, perlu adanya program pemberdayaan bagi kelembagaan tersebut, sehingga harapannya dapat aktif melakukan kegiatan konservasi. Pengelolaan DAS harus dilakukan secara terpadu dan terkoordinasi, terutama dalam membina kelembagaan masyarakat agar terjadi partisipasi yang berkelanjutan (Sudaryono 2002). Selain itu dari sisi kebijakan, Pemerintah Kabupaten Bogor telah memiliki payung hukum dalam perlindungan dan pengelolaan DAS Daerah Aliran Sungai (DAS) berupa PerDa Kabupaten Bogor Nomor 6 tahun 2016 tentang Pengelolaan Lingkungan Hidup yang menjelaskan tujuan dari kebijakan perlindungan dan pengelolaan DAS dilaksanakan dengan pertimbangan pembangunan berkelanjutan secara menyeluruh, konsisten, memadukan perlindungan lingkungan, pertumbuhan ekonomi dan sosial.

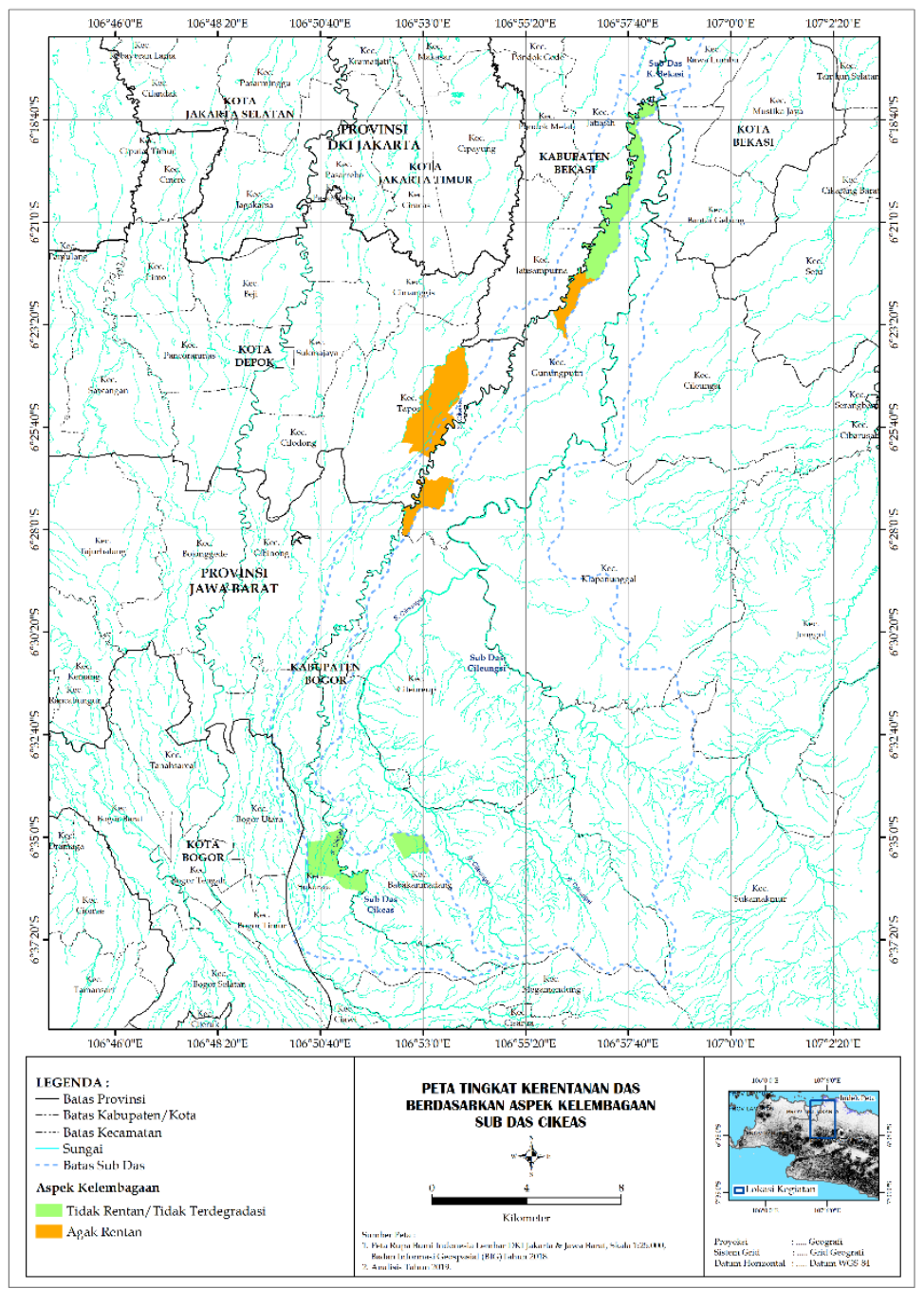

Gambar 5. Tingkat kerentanan DAS Cikeas berdasarkan indikator kelembagaan. 


\section{KESIMPULAN DAN SARAN}

Tingkat kerentanan DAS Kali Cikeas ditinjau dari aspek sosial (kepadatan penduduk dan nilai tradisional) berada pada kategori sangat tinggi dan sangat rentan. Perilaku konservasi termasuk tidak rentan dan agak rentan. Pada aspek ekonomi, mayoritas kecamatan di wilayah DAS Kali Cikeas tergolong agak rentan, karena sektor ekonomi dominan berupa jasa. Ditinjau dari aspek kelembagaan, DAS Kali Cikeas tergolong tidak rentan dan agak rentan karena terdapat kelembagaan formal dan informal yang telah berperan aktif dalam aktivitas konservasi DAS Kali Cikeas. Permasalahan DAS berkaitan dengan kepedulian masyarakat terhadap pengelolaan lingkungan. Dengan demikian, keterlibatan masyarakat dan stakeholder terkait lainnya dalam perencanaan, perumusan, pelaksanaan kebijakan DAS sangat diperlukan untuk mencapai pengelolaan DAS berkelanjutan.

\section{UCAPAN TERIMAKASIH}

Ucapan terima kasih disampaikan pada Direktorat Jenderal Pengendalian Pencemaran dan Kerusakan Lingkungan, Kementerian Lingkungan Hidup dan Kehutanan yang telah memfasilitasi penelitian ini.

\section{DAFTAR PUSTAKA}

[BPS] Badan Pusat Statistik Kabupaten Bogor. 2019. Kabupaten Bogor dalam angka 2019. BPS Kabupaten Bogor. Bogor.

[BPS] Badan Pusat Statistik Kota Bekasi. 2019. Kota Bekasi dalam angka 2019. BPS Kota Bekasi. Bekasi.

[BPS] Badan Pusat Statistik Kota Depok. 2019. Kota Depok dalam angka 2019. BPS Kota Depok. Depok.

Du Y, Wang X, Brombal D, Moriggi A, Sharpley A and Pang S. 2018. Changes in environmental awareness and its connection to local environmental management in water conservation zones: the case of Beijing, China. Sustainability 10(6):1-24.

Ekawaty R, Yonariza, Ekaputra EG and Arbain A. 2018. Telaahan daya dukung dan daya tampung lingkungan dalam pengelolaan kawasan daerah aliran sungai di Indonesia. Journal of Applied Agricultural Science and Technology 2(2):30-40.

Goldshleger N, Ben-Dor E, Lugassi R and Eshel G. 2010. Soil degradation monitoring by remote sensing: examples with three degradation processes. Soil Science Society of American Journal 74:1433-1445.

Komaruddin N. 2008. Penilaian tingkat bahaya erosi di sub daerah aliran Sungai Cileungsi, Bogor. Jurnal Agrikultura 19(3):173-178. 
Paimin, Pramono IB, Purwanto dan Indrawati DR. 2012. Sistem perencanaan pengelolaan daerah aliran sungai. Pusat Penelitian dan Pengembangan Konservasi dan Rehabilitasi. Bogor

PerDa (Peraturan Daerah) Kabupaten Bogor Nomor 6 Tahun 2016 tentang pengelolaan lingkungan hidup.

PerMenLH (Peraturan Menteri Lingkungan Hidup) Nomor 1 Tahun 2010 tentang tata laksana pengendalian pencemaran.

Prasetyo K, Prayoga G, Azhar AR, Permadi T dan Pratiwi D. 2020. Kerentanan DAS Kali Bekasi ditinjau dari aspek sosial-ekonomi-kelembagaan. Jurnal Pengelolaan Lingkungan Berkelanjutan 4(3):576-591.

Siswadi, Taruna T dan Purnaweni H. 2011. Kearifan lokal dalam melestarikan mata air. Jurnal Ilmu Lingkungan 9(2):63-68.

Sudaryono. 2002. Pengelolaan daerah aliran sungai (DAS) terpadu, konsep pembangunan berkelanjutan. Jurnal Teknologi Lingkungan 3(2):153-158.

Sugiyono. 2016. Metode penelitian kuantitatif, kualitatif dan R\&D. PT Alfabet. Bandung.

Suparjo MN. 2009. Kondisi pencemaran perairan Sungai Babon Semarang. Jurnal Saintek Perikanan 4(2):38-45.

Susilowati W, Damianto B, Nadjam A dan Nurhayati I. 2012. Peran serta masyarakat dalam meningkatkan kualitas lingkungan daerah aliran Sungai Ciliwung. Poli-Teknologi 11(1):55-64.

Symeonakis E, Calvo-Cases A and Arnau-Rosalen E. 2007. Land use change and land degradation in Southeastern Mediterranean Spain. Environmental Management 40:80-94.

Tafangenyasha C and Dzinomwa T. 2005. Land-use Impacts on river water quality in lowveld sand river systems in South-East Zimbabwe. Land Use and Water Resources Research 5:3.1-3.10. 